\title{
BMJ
}

\section{Influence of moving to the UK on maternal health behaviours: prospective cohort study}

\author{
Summer Sherburne Hawkins, research fellow, Kate Lamb, MSc student, Tim J Cole, professor, \\ Catherine Law, professor, the Millennium Cohort Study Child Health Group
}

Centre for Paediatric Epidemiology and Biostatistics, UCL Institute of Child Health, London WC1N 1EH

Correspondence to: S S Hawkins s.hawkins@ich.ucl.ac.uk

doi:10.1136/bmj.39532.688877.25

\section{ABSTRACT}

Objective To compare health behaviours during pregnancy (smoking and alcohol consumption) and after birth (initiation and duration of breast feeding) between British/Irish white mothers and mothers from ethnic minority groups; and, in mothers from ethnic minority groups, to examine whether indicators of acculturation (generational status, language spoken at home, length of residency in the United Kingdom) were associated with these health behaviours.

Design Prospective nationally representative cohort study. Setting England.

Participants 6478 British/Irish white mothers and 2110 mothers from ethnic minority groups.

Main outcome measures Any smoking during pregnancy; any alcohol consumption during pregnancy; initiation of breast feeding; breast feeding for at least four months.

Results Compared with British/Irish white mothers, mothers from ethnic minority groups were less likely to smoke (15\% v 37\%) or consume alcohol (14\% v 37\%) during pregnancy but more likely to initiate breast feeding ( $86 \%$ v $69 \%$ ) and breast feed for at least four months ( $40 \%$ $v 27 \%)$. Among mothers from ethnic minority groups, first and second generation mothers were more likely to smoke during pregnancy (odds ratio $3.85,95 \%$ confidence interval 2.50 to 5.93 , and $4.70,2.49$ to 8.90 , respectively), less likely to initiate breast feeding $(0.92,0.88$ to 0.97 , and $0.86,0.75$ to 0.99 ), and less likely to breast feed for at least four months $(0.72,0.62$ to 0.83 , and $0.52,0.30$ to 0.89 ) than immigrants, after adjustment for sociodemographic characteristics. There were no consistent differences in alcohol consumption. Among immigrants, for every additional five years spent in the UK the likelihood of mothers smoking during pregnancy increased by $31 \%$ ( $4 \%$ to $66 \%$ ) and they were $5 \%(0 \%$ to $10 \%)$ less likely to breast feed for at least four months.

Conclusions After immigration, maternal health behaviours worsen with length of residency in the UK. Health professionals should not underestimate women's likelihood of engaging in risky health behaviours because of their ethnicity.

\section{INTRODUCTION}

The adverse effects of smoking ${ }^{12}$ and alcohol consumption $^{3}$ during pregnancy and the beneficial effects of breast feeding ${ }^{4}$ on maternal and child health are well known. Many women from resource-rich countries, however, do not adhere to recommendations, ${ }^{15-10}$ including those to reduce smoking $^{112}$ and stop drinking ${ }^{13}$ during pregnancy and breast feed exclusively for six months. ${ }^{14}$ Research from the United States has shown that maternal health behaviours vary by country of birth and length of residency, two indicators of acculturation. ${ }^{15-24}$ Acculturation is the adoption of health behaviours from the new dominant culture and loss of health behaviours from the original culture. ${ }^{2526}$ In the US, acculturation has been associated with an increase in smoking ${ }^{15-18}$ and alcohol consumption ${ }^{15-17}$ during pregnancy as well as a reduction in initiation ${ }^{19-24}$ and duration ${ }^{192324}$ of breast feeding.

Over the past 50 years immigration into the United Kingdom has increased, primarily from South Asia, the Caribbean, Europe, and Africa. ${ }^{27}$ In 2001-2, 7.6\% of the population was from an ethnic minority group, an increase of $44 \%$ over the previous decade. ${ }^{28}$ Women from ethnic minority groups are less likely to smoke or consume alcohol than the general population in England $^{29}$ and more likely to initiate and continue breast feeding than white mothers. ${ }^{7}$

We compared health behaviours during pregnancy (smoking and alcohol consumption) and after birth (initiation and duration of breast feeding) between British/Irish white mothers and mothers from ethnic minority groups in a nationally representative, contemporary cohort of mothers in England. We also examined how indicators of acculturation (measured by generational status, language spoken at home, length of residency in the UK) were associated with these health behaviours.

\section{METHODS}

Participants

The millennium cohort study is a prospective study of children born in the UK in the new century. We used a stratified clustered sampling framework to overrepresent children from ethnic minority groups and disadvantaged areas. In England, electoral wards (as established in 1998) were categorised as "ethnic" (based on the 1991 census, if at least $30 \%$ of residents 
were from an ethnic minority group) and the remainder as "disadvantaged" (the upper quarter of the child poverty index) or "advantaged" (all remaining wards). In Wales, Scotland, and Northern Ireland there was no "ethnic" stratum. ${ }^{30}$ Families were invited to participate if they were eligible for child benefit and resident in the UK when their child was aged 9 months. The original cohort comprised 18819 children (18553 families) born between September 2000 and January 2002 (72\% response)..$^{30}$ About $80 \%$ (14630) participated in the second contact, in September 2003 to January 2005, when the children were aged 3 years. ${ }^{31}$ At both contacts, information was collected through interviews of main respondents in the home. Translators were available. $^{32}$

We focused on families in England because numbers were insufficient to analyse by ethnic group in Wales, Scotland, or Northern Ireland. Among the 11695 mothers with singleton children at the first contact, 79\% (9184) participated in the second. Families from "ethnic" and "disadvantaged" electoral wards were less likely to participate in the second contact, ${ }^{31}$ but non-response weights are available and were used to allow for differential attrition. Data were accessed through the UK Data Archive, University of Essex.

Among the 9184 mothers with singleton children in England at both contacts, we included 8588 in the analyses. We excluded families if information was missing on the main respondent's ethnicity (46), the main respondent was not female (139) or a natural mother (53), there were two cohort children from the same family (8), or the main respondent had missing information on her generational status (370), language spoken at home (0), length of residency in the UK(193), initiation of breast feeding (15), duration of breast feeding (15), smoking during pregnancy (41), or alcohol consumption during pregnancy (16). Some families satisfied more than one exclusion criterion.

At the first contact, mothers reported their own ethnicity (out of 16 possible choices), which was classified according to guidelines from the Office for National Statistics. ${ }^{33}$ White women were categorised as either from any UK country or the Republic of Ireland (referred to as "British/Irish") or from any other country (referred to as "other white"). ${ }^{5}$ To increase sample size we collapsed ethnic groups into British/ Irish white, Pakistani or Bangladeshi, black (black African, black Caribbean, other black), Indian, other white (such as white European, North American), other (such as Sri Lankan, Arab), or mixed.

Sociodemographic characteristics were based on maternal self report at the first contact. Maternal socioeconomic circumstances were categorised according to the National Statistics socioeconomic classification, ${ }^{34}$ maternal education was defined as the highest academic qualification attained, and single motherhood status was defined as being a single mother when the child was aged 9 months. Mothers also reported whether the cohort child was their first live birth (parity), and their age at the birth of the cohort child. We included family income at the first contact; if it was missing we substituted values from the second contact (483).

\section{Outcome measures}

Smoking and alcohol consumption during pregnancy-At the first contact, mothers were asked about their smoking and drinking habits during pregnancy. Mothers reported their smoking habits before pregnancy and were asked whether they changed during pregnancy. Mothers were classified as having smoked if they reported smoking any number of cigarettes during pregnancy. Mothers also reported how often they drank alcoholduring pregnancy, ranging from never to every day. Mothers were classified as having consumed alcohol if they reported consuming any amount of alcohol during pregnancy. At the time when the mothers were pregnant, government recommendations were that pregnant women should drink no more than one or two units of alcohol once or twice a week and avoid intoxication. ${ }^{35}$

Initiation and duration of breast feeding - At the first contact, mothers were asked about their infant feeding practices. Initiation of breast feeding was defined as the baby having received any breast milk. Duration was categorised as being either fully or partially breast fed for at least four calendar months $(\geq 17.4$ weeks) or less than four months. ${ }^{5}$ At the time of the cohort births, the World Health Organization recommended that babies were breast fed for at least four months. ${ }^{36}$

\section{Indicators of acculturation}

Generational status - At the second contact, main respondents reported whether they, their mother, and their father were born in the UK or Republic of Ireland and, if not, their country of birth. Mothers were classified as immigrants (neither they nor either parent were born in the UK or Republic of Ireland), first generation (they were born in the UK or Republic of Ireland, but at least one parent was born outside the UK or Republic of Ireland), or second generation (both they and their parents were born in the UK or Republic of Ireland).

Language spoken at home-At the first contact, main respondents reported whether the language usually spoken at home was English, English and another language, or another language only.

Length of residency in the UK-At the second contact, main respondents who were not born in the UK or Republic of Ireland were asked the year when they arrived in the UK. This was subtracted from the year of the interview at the first contact to give the length of residency.

\section{Statistical analyses}

All analyses were conducted with STATA statistical software, version 9.2 SE (Stata Corporation, TX), with survey commands to account for the clustered sampling framework and obtain robust standard errors. We derived weighted percentages and conducted analyses using survey and non-response weights to allow for the 
clustered sampling and attrition between contacts. Proportions were compared with Pearson's $\chi^{2}$ tests with the Rao and Scott second order correction. ${ }^{37} \mathrm{We}$ included British/Irish white mothers to provide baseline characteristics of the majority ethnic group in England. Health behaviours during pregnancy (smoking and alcohol consumption) and after birth (initiation and duration of breast feeding) were compared by maternal ethnic group.

Adjusted regression analyses were conducted to examine the relations between mothers' ethnicity (British/Irish white mothers versus all mothers from ethnic minority groups) and health behaviours during pregnancy and after birth. We adjusted analyses for socioeconomic circumstances, family income, highest academic qualification, single motherhood, age at cohort birth, and parity. Subsequent analyses focused on mothers from ethnic minority groups, who were combined, as our hypothesis was related to acculturation in general regardless of country of origin. We conducted univariable regression analyses to examine the relations between indicators of acculturation (measured by mothers' generational status, language spoken at home) and health behaviours during pregnancy and after birth. Logistic regression analyses were conducted to calculate odds ratios for smoking and alcohol consumption during pregnancy by both indicators of acculturation. As odds ratios often overestimate the relative risk when an outcome is relatively common, ${ }^{38}$ we used modified Poisson regression ${ }^{39}$ to calculate rate ratios for initiation and duration of breast feeding by both indicators of acculturation. We subsequently adjusted analyses for the sociodemographic characteristics already listed. As acculturation might vary according to ethnicity, we also adjusted for maternal ethnic group. Analyses were repeated for immigrants only to examine the relation between length of residency in the UK and health behaviours during pregnancy and after birth.

\section{RESULTS}

Table 1 presents indicators of acculturation for mothers from ethnic minority groups and health behaviours during pregnancy and after birth for British/Irish white mothers and mothers from ethnic minority groups. Indicators of acculturation and health behaviours varied by maternal ethnic group. Compared with British/Irish white mothers, mothers from ethnic minority groups were less likely to smoke or drink alcohol during pregnancy but more likely to start breast feeding or breast feed for at least four months. These differences persisted after adjustment for sociodemographic characteristics. Mothers from ethnic minority groups were less likely to smoke (odds ratio (baseline British/Irish white mothers) 0.27, 95\% confidence interval 0.21 to 0.35 ) or drink alcohol $(0.34,0.28$ to 0.42$)$ during pregnancy but more likely to start breast feeding (rate ratio $1.35,1.30$ to 1.40 ) or breast feed for at least four months $(1.71,1.54$ to 1.88$)$.

A comparison between mothers' generational status and language spoken at home showed similarities between the two measures. Among immigrants, 18\% spoke only English, 58\% spoke English and another language, and 24\% spoke only another language; among second generation mothers, these values were $88 \%, 12 \%$, and $0 \%$, respectively.

In general, British/Irish white mothers and first and second generation mothers had more advantaged sociodemographic profiles than immigrants (table 2). Family income levels, however, were similar between immigrants and first and second generation mothers, while British/Irish white mothers had higher income levels. The prevalence of single motherhood was similar between immigrants and British/Irish white mothers but higher for first and second generation mothers.

Table 1 | Indicators of acculturation and health behaviours among mothers in the millennium cohort study. Figures are numbers (percentages*) of women

\begin{tabular}{|c|c|c|c|c|c|c|c|}
\hline $\begin{array}{c}\text { British/Irish } \\
\text { white } \\
(n=6478)\end{array}$ & $\begin{array}{c}\text { All ethnic } \\
\text { minority } \\
\text { groups } \\
(n=2110)\end{array}$ & $\begin{array}{c}\text { Pakistani or } \\
\text { Bangladeshi } \\
(n=849)\end{array}$ & $\begin{array}{c}\text { Black } \\
(n=402)\end{array}$ & $\begin{array}{c}\text { Indian } \\
(n=348)\end{array}$ & $\begin{array}{c}\text { Other white } \\
(n=207)\end{array}$ & $\begin{array}{c}\text { Other } \\
(n=204)\end{array}$ & $\begin{array}{c}\text { Mixed } \\
(\mathrm{n}=100)\end{array}$ \\
\hline
\end{tabular}

Indicators of acculturation

Generational status:

\begin{tabular}{|c|c|c|c|c|c|c|c|c|}
\hline Immigrant & - & $1374(63)$ & $589(68)$ & $221(51)$ & $187(50)$ & $171(79)$ & $180(88)$ & $26(27)$ \\
\hline 1st generation & - & $681(33)$ & $258(32)$ & $170(46)$ & $158(49)$ & $18(10)$ & $22(11)$ & $55(51)$ \\
\hline 2nd generation & - & $55(4)$ & $2(0.2)$ & $11(3)$ & $3(1)$ & $18(11)$ & $2(0.7)$ & $19(23)$ \\
\hline \multicolumn{9}{|l|}{ Language spoken at home: } \\
\hline English only & - & $533(32)$ & $32(5)$ & $247(64)$ & $61(22)$ & $83(45)$ & $42(22)$ & $68(70)$ \\
\hline English and other language & - & $1171(51)$ & $579(68)$ & $121(28)$ & $230(65)$ & $100(44)$ & $117(52)$ & $24(23)$ \\
\hline Other language only & - & $406(17)$ & $238(27)$ & $34(8)$ & $57(13)$ & $24(12)$ & $45(26)$ & $8(7)$ \\
\hline \multicolumn{9}{|l|}{ Outcome measures } \\
\hline Smoked during pregnancy† & $2402(37)$ & $262(15)$ & $38(4)$ & $80(22)$ & $18(6)$ & $60(30)$ & $24(14)$ & $42(41)$ \\
\hline Consumed alcohol during pregnancy† & $2388(37)$ & $204(14)$ & $1(0)$ & $70(20)$ & $29(12)$ & $62(34)$ & $21(12)$ & $21(22)$ \\
\hline Started breast feeding $†$ & $4461(69)$ & $1791(86)$ & $654(76)$ & $377(95)$ & $299(86)$ & $189(92)$ & $184(92)$ & $88(88)$ \\
\hline Breast fed for at least 4 months $†$ & $1716(27)$ & $779(40)$ & $209(26)$ & $190(50)$ & $142(41)$ & $97(47)$ & $104(56)$ & $37(38)$ \\
\hline
\end{tabular}


Table 2 Sociodemographic characteristics by generational status for all mothers in the millennium cohort study. Figures are numbers (percentages*) of women

$\begin{array}{ccc}\text { Immigrant } & \begin{array}{c}\text { 1st and 2nd } \\ \text { generation }\end{array} & \text { British/Irish white } \\ (\mathrm{n}=1374) & (\mathrm{n}=736) & (\mathrm{n}=6478)\end{array}$

Sociodemographic characteristics

Maternal socioeconomic circumstances:

\begin{tabular}{lccc}
\hline Managerial/professional occupations & $174(18)$ & $176(30)$ & $2020(32)$ \\
\hline Small employers/own account workers & $29(3)$ & $28(5)$ & $275(5)$ \\
\hline Intermediate occupations & $122(10)$ & $146(19)$ & $1232(20)$ \\
\hline Lower supervisory/ technical occupations & $42(3)$ & $28(4)$ & $362(5)$ \\
\hline Semi-routine/routine occupations & $365(27)$ & $251(32)$ & $2270(35)$ \\
\hline Never worked/long term unemployed & $624(39)$ & $93(11)$ & $253(4)$ \\
\hline Missing & 18 & 14 & 66 \\
\hline
\end{tabular}

Family income/year (£):

\begin{tabular}{lccc}
\hline $0-11000$ & $448(34)$ & $297(36)$ & $1256(19)$ \\
\hline $11000-22000$ & $461(35)$ & $214(29)$ & $2045(31)$ \\
\hline $22000-33000$ & $173(14)$ & $98(16)$ & $1535(24)$ \\
\hline$\geq 33000$ & $165(18)$ & $104(19)$ & $1556(25)$ \\
\hline Missing & 127 & 23 & 86 \\
\hline
\end{tabular}

Highest academic qualification in mother:

\begin{tabular}{lccc}
\hline GCSE† grades A-C or higher & $740(60)$ & $504(72)$ & $4838(75)$ \\
\hline GCSE† grades D-G or lower & $632(40)$ & $229(28)$ & $1633(25)$ \\
\hline Missing & 2 & 3 & 7
\end{tabular}

\section{Missing}

\begin{tabular}{lccc}
\hline No & $1201(87)$ & $578(79)$ & $5622(87)$ \\
\hline Yes & $173(13)$ & $158(21)$ & $856(13)$ \\
\hline Missing & 0 & 0 & 0 \\
\hline Age at cohort birth (years): & $29(0.3)$ & $28(0.5)$ & $29(0.1)$ \\
\hline Mean (SE) & 2 & 0 & 0 \\
\hline Missing & & & \\
\hline Was cohort child first live born: & $374(32)$ & $317(44)$ & $2800(43)$ \\
\hline Yes & $931(68)$ & $409(56)$ & $3661(57)$ \\
\hline No & 69 & 10 & 17 \\
\hline Missing & & & \\
\hline
\end{tabular}

*Weighted percentage.

tQualification taken by secondary school students aged about $14-16$ years.

We examined relations between the indicators of acculturation and maternal health behaviours among mothers from ethnic minority groups (table 3). First and second generation mothers were more likely to smoke during pregnancy than immigrants, and there was a gradient by generation $(\mathrm{P}<0.001$ for trend). Mothers who spoke only English at home were more likely to smoke during pregnancy than mothers who spoke only another language. Both relations were maintained after adjustment for sociodemographic characteristics. In unadjusted analyses, first and second generation mothers were more likely to drink alcohol during pregnancy than immigrants. Mothers who spoke English and another language at home and only English at home were more likely to drink alcohol than mothers who spoke only another language. After adjustment, risk of alcohol consumption during pregnancy was still significantly increased for mothers who spoke only English at home but was attenuated considerably.

In unadjusted analyses there were no differences in initiation or duration of breast feeding by the indicators of acculturation, except that first and second generation mothers were less likely to breast feed for at least four months than immigrants. After adjustment for sociodemographic factors, however, first and second generation mothers were less likely to start breast feeding than immigrants and the relation between generational status and duration of breast feeding strengthened. Gradients were evident by generational status $(\mathrm{P}<0.001$ for trend in adjusted analyses). Mothers who spoke only English at home were less likely to start or continue breast feeding than mothers who spoke only another language.

Immigrants had lived in the UK for a median of nine years (interquartile range 4-15). Among immigrants, maternal health behaviours varied by length of residency in the UK (table 4). After adjustment for sociodemographic factors, for every additional five years in the UK mothers were $31 \%$ more likely to smoke during pregnancy and 5\% less likely to breast feed for at least four months. There was no association between length of residency and alcohol consumption or initiation of breast feeding.

\section{DISCUSSION}

Among a contemporary cohort in England, 63\% of mothers from ethnic minority groups were immigrants and 33\% were first generation (that is, born in the UK or Republic of Ireland but with at least one parent born in another country). Compared with British/Irish white mothers, mothers from ethnic minority groups were less likely to smoke or drink alcohol during pregnancy and more likely to initiate breast feeding and breast feed for at least four months. Among mothers from ethnic minority groups, first and second generation mothers were more likely to smoke during pregnancy than immigrants, but less likely to start breast feeding or breast feed for at least four months. The relations with smoking during pregnancy and duration of breast feeding were evident before and after adjustment for sociodemographic characteristics. First and second generation mothers were also more likely to consume alcohol during pregnancy, but associations were apparent only in unadjusted analyses. There were fewer consistent patterns when we used language spoken at home as an indicator of acculturation. Immigrants who had lived in the UK for longer were more likely to smoke during pregnancy and less likely to breast feed for at least four months than those who had arrived more recently.

\section{Strengths and limitations}

The breadth of information collected on families in the millennium cohort study provided an opportunity to investigate whether indicators of acculturation were related to maternal health behaviours. Because of small numbers we had to combine some ethnic minority groups when making statistical adjustment. These combined groups might be heterogeneous with respect to maternal characteristics related to acculturation or health behaviours and so our findings might not be generalisable to mothers from all ethnic minority 
groups in England. Future cohort studies should ensure adequate samples of mothers from ethnic minority groups through over-representation during recruitment as well as investment of resources to reduce attrition and to allow analysis by ethnic group.

Main respondents were interviewed and provided detailed information on sociodemographic characteristics, health behaviours during pregnancy, and infant feeding practices. Although self reported information on breast feeding has been found to be reliable and valid, ${ }^{40}$ smoking and alcohol consumption during pregnancy might be under-reported. ${ }^{41-43}$ Objective measures provide more accurate assessment but are not feasible in large scale surveys. If under-reporting

Table 3 | Unadjusted and adjusted risk ratios (or odds ratios $\left.{ }^{\star}\right)(95 \% \mathrm{Cl})$ for health behaviours among mothers from ethnic minority groups, according to indicators of acculturation

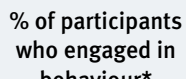

Unadjusted

Adjusted $\ddagger$

Smoking during pregnancy

Generational status:

\begin{tabular}{lccc}
\hline Immigrant & 9 & 1 & 1 \\
\hline 1st generation & 23 & $2.92(2.07$ to 4.13$)$ & 3.85 (2.50 to 5.93) \\
\hline 2nd generation & 54 & $11.47(6.24$ to 21.09) & 4.70 (2.49 to 8.90) \\
\hline Language spoken at home: & & & \\
\hline Other language only & 7 & 1 & 1 \\
\hline English and other language & 8 & $1.19(0.67$ to 2.14$)$ & $1.69(0.80$ to 3.56) \\
\hline English only & 31 & $5.81(3.32$ to 10.16) & $4.19(1.94$ to 9.09) \\
\hline
\end{tabular}

Alcohol consumption during pregnancy

Generational status:

\begin{tabular}{llcc}
\hline Immigrant & 11 & 1 & 1 \\
\hline 1st generation & 16 & $1.50(1.04$ to 2.16$)$ & $1.43(0.88$ to 2.33$)$ \\
\hline 2nd generation & 35 & $4.28(2.05$ to 8.94$)$ & $1.96(0.88$ to 4.37$)$ \\
\hline
\end{tabular}

Language spoken at home:

\begin{tabular}{lccc}
\hline Other language only & 4 & 1 & 1 \\
\hline English and other language & 9 & $2.36(1.20$ to 4.64) & 1.39 (0.68 to 2.86) \\
\hline English only & 27 & $9.49(4.05$ to 22.23$)$ & $2.55(1.05$ to 6.21) \\
\hline
\end{tabular}

Breast feeding initiation

Generational status:

\begin{tabular}{llcc}
\hline Immigrant & 87 & 1 & 1 \\
\hline 1st generation & 85 & $0.99(0.94$ to 1.03$)$ & $0.92(0.88$ to 0.97$)$ \\
\hline 2nd generation & 83 & $0.96(0.83$ to 1.10$)$ & $0.86(0.75$ to 0.99$)$ \\
\hline Language spoken at home: & & & \\
\hline Other language only & 84 & 1 & 1 \\
\hline English and other language & 85 & $1.01(0.94$ to 1.08$)$ & $0.96(0.91$ to 1.02$)$ \\
\hline English only & 89 & $1.06(0.99$ to 1.14$)$ & $0.88(0.83$ to 0.95$)$ \\
\hline
\end{tabular}

Breast feeding for at least 4 months

Generational status:

\begin{tabular}{llcc}
\hline Immigrant & 44 & 1 & 1 \\
\hline 1st generation & 35 & $0.79(0.69$ to 0.90$)$ & $0.72(0.62$ to 0.83$)$ \\
\hline 2nd generation & 26 & $0.59(0.36$ to 0.98$)$ & $0.52(0.30$ to 0.89$)$ \\
\hline Language spoken at home: & & & \\
\hline Other language only & 38 & 1 & 1 \\
\hline English and other language & 39 & $1.02(0.87$ to 1.20$)$ & $0.87(0.74$ to 1.03$)$ \\
\hline English only & 44 & $1.14(0.93$ to 1.40$)$ & $0.76(0.63$ to 0.93$)$ \\
\hline
\end{tabular}

*Weighted percentage.

†Odds ratios for smoking and alcohol consumption during pregnancy; rate ratios for initiation of breast feeding and breast feeding for at least 4 months.

$\ddagger$ Adjusted for ethnic group, socioeconomic circumstances, family income, highest academic qualification, single motherhood, age at cohort birth, parity. occurred, we have probably underestimated the size of the relations between the indicators of acculturation and alcohol use and smoking during pregnancy. At the time when the cohort mothers were pregnant, women were advised to drink no more than one or two units of alcohol a week. ${ }^{35}$ We were not able to examine compliance with this recommendation because only a limited number of women from ethnic minority groups reported drinking any alcohol during pregnancy. Our definition of alcohol use, however, is consistent with current recommendations. ${ }^{1344}$ The cohort study was not designed to assess acculturation, so we used generational status, language spoken at home, and length of residency as indicators. Though validated questionnaires are available to assess acculturation, ${ }^{2526}$ country of birth, ${ }^{15-17} 19202223$ language, ${ }^{21}$ and length of residency ${ }^{182324}$ have been used in research from the US. These measures are likely to be easier for large scale studies and for health professionals to use and interpret than specific questionnaires.

\section{Comparison with literature}

Our findings agree with those of previous studies in the US, which have reported that mothers with greater acculturation are more likely to smoke ${ }^{15-18}$ and drink alcohol ${ }^{15-17}$ during pregnancy and less likely to start ${ }^{19-24}$ or continue $\mathrm{e}^{192324}$ breast feeding. Similar to a study in the US, we found that an association between generational status and alcohol consumption during pregnancy was no longer evident after we adjusted for sociodemographic characteristics. ${ }^{16}$ We did, however, find that mothers who spoke only English were more likely to drink alcohol during pregnancy than mothers who spoke only another language, before and after adjustment. In the UK, ethnic differences in alcohol consumption are likely to be because of cultural or religious beliefs. ${ }^{45}$ Some of these relations have been examined in a cohort of Pacific Island infants in New Zealand. Mothers were more likely to smoke during pregnancy $^{46}$ and less likely to breast feed exclusively ${ }^{47}$ with a longer residency in New Zealand, which the authors noted could be a result of "exposure to Westernisation." ${ }^{46}$ Research on acculturation has public health implications for other countries with large immigrant populations. It will be important to determine whether our results and the US findings can be replicated in other countries.

\section{Implications for practice and policy}

Health professionals should not underestimate the likelihood of women engaging in risky health behaviours because of their ethnicity. Little is known about how "western" cultures can affect changes in health behaviours among women who have recently migrated. Although antenatal care is associated with healthy behaviour during pregnancy and after birth, ${ }^{1623}$ use of health services does not seem to be responsible for differences by generational status. In the millennium cohort study, only $3 \%$ of mothers from England received no antenatal care, but this ranged from $2 \%$ of British/Irish white mothers to $4 \%$ of first 
Table 4 | Unadjusted and adjusted risk ratios (or odds ratios*) $(95 \% \mathrm{Cl})$ for health behaviours among immigrants from ethnic minority groups, for every five years spent in UK

\begin{tabular}{lcc} 
Smoking during pregnancy & Unadjusted & Adjusted $†$ \\
\hline Alcohol consumption during pregnancy & $1.03(0.87$ to 1.22$)$ & 1.31 (1.04 to 1.66$)$ \\
\hline Initiation of breast feeding & $1.01(0.89$ to 1.15$)$ & $1.00(0.83$ to 1.22$)$ \\
\hline Breast feeding for at least 4 months & $1.00(0.98$ to 1.02$)$ & 1.00 (0.98 to 1.01$)$ \\
\hline
\end{tabular}

*Odds ratios for smoking and alcohol consumption during pregnancy; rate ratios for initiation of breast feeding and breast feeding for at least 4 months.

†Adjusted for ethnic group, socioeconomic circumstances, family income, highest academic qualification, single motherhood, age at cohort birth, parity.

and second generation mothers to $10 \%$ of immigrants $(\mathrm{P}<0.001$; data not shown). We found that mothers' engagement in beneficial health behaviours decreased with length of residency in the UK. As families settle in the UK, it will be important to support the maintenance of healthy behaviours among women, their daughters, and future generations. Intention to breast feed also varies with acculturation, suggesting the need for interventions before or early in pregnancy. ${ }^{48}$

National policies should promote beneficial health behaviours among all mothers. Recommendations have been modified since the cohort children were born. Mothers in England are now recommended to avoid all alcohol during pregnancy ${ }^{44}$ and breast feed exclusively for at least six months, ${ }^{14}$ which is consistent with polices in other resource-rich countries. The UK government also has a target to reduce smoking during pregnancy. ${ }^{11}$ In England, public smoking restrictions were introduced in July $2007 .{ }^{49}$ Reductions in smoking have been reported in other countries and cities with a ban. ${ }^{50}$ Policies to protect breast feeding in public have been established in Scotland ${ }^{51}$ and some states in the US, ${ }^{52}$ and legislation has been proposed in England. ${ }^{53}$ Evaluation of how such policies influence maternal health behaviours, however, has been limited, including by ethnic group or acculturation. Policy evaluation will be critical to ensure that all mothers can achieve recommendations to foster their own and their children's health.

We thank all of the millennium cohort study families for their cooperation and the study team at the Centre for Longitudinal Studies, Institute of Education, University of London.

\section{WHAT IS ALREADY KNOWN ON THIS TOPIC}

The United Kingdom has experienced an increase in immigration over the past 50 years

Compared with British/Irish white women, women from ethnic minority groups are more likely to breast feed, but there is no information on their use of alcohol or tobacco during pregnancy or whether their health behaviours change with acculturation

\section{WHAT THIS STUDY ADDS}

Mothers from ethnic minority groups are less likely overall to use tobacco and alcohol during pregnancy than British/Irish white mothers

Maternal health behaviours worsen (smoking during pregnancy and lack of breast feeding) with length of residency in the UK, an indicator of acculturation

Health professionals should not underestimate women's likelihood of engaging in risky health behaviours because of their ethnicity
Contributors: $\mathrm{SSH}$ and $\mathrm{CL}$ contributed to the conception, study design, interpretation of the data, and first draft of the article. SSH, KL, and TJC contributed to the analysis. TJC and $\mathrm{KL}$ also contributed to the interpretation of the data and drafting of the article. All authors approved the final version. SSH is guarantor. Other members of the millennium cohort study child health group (Carol Dezateux, Catherine Peckham, Jugnoo Rahi, Helen Bedford, Phillippa Cumberland, Lucy Jane Griffiths, Anna Pearce, Suzanne Bartington) also contributed to this work. Funding: The millennium cohort study is funded by grants to Heather Joshi, director of the study, from the ESRC and a consortium of government funders. SSH is funded through a Department of Health Researcher Development Award. KL received funding from the North London Deanery. TJC is funded through an MRC programme grant (G9827821). This work was undertaken at GOSH/UCL Institute of Child Health, which received a proportion of funding from the Department of Health's NIHR Biomedical Research Centres funding scheme.

Competing interests: None declared.

Ethical approval: The millennium cohort study received ethical approval from the South West and London multi-centre research ethics committees; no additional approval was required for this study. Provenance and peer review: Not commissioned; externally peer reviewed.

1 Ventura SJ, Hamilton BE, Mathews TJ, Chandra A. Trends and variations in smoking during pregnancy and low birth weight: evidence from the birth certificate, 1990-2000. Pediatrics 2003;111:1176-80.

2 Hofhuis W, de Jongste JC, Merkus PJFM. Adverse health effects of prenatal and postnatal tobacco smoke exposure on children. Arch Dis Child 2003;88:1086-90.

3 Mattson SN, Riley EP. A review of the neurobehavioral deficits in children with fetal alcohol syndrome or prenatal exposure to alcohol. Alchol Clin Exp Res 1998;22:279-94.

4 Gartner LM, Morton J, Lawrence RA, Naylor AJ, O'Hare D, Schanler RJ, et al. Breastfeeding and the use of human milk. Pediatrics 2005;115:496-506.

5 Griffiths LI, Tate AR, Dezateux C, the Millennium Cohort Study Child Health Group. The contribution of parental and community ethnicity to breastfeeding practices: evidence from the Millennium Cohort Study. Int J Epidemiol 2005;34:1378-86.

6 Mohsin M, Bauman AE. Socio-demographic factors associated with smoking and smoking cessation among 426,344 pregnant women in New South Wales, Australia. BMC Public Health 2005;5:138.

7 Bolling K, Grant C, Hamlyn B, Thornton A. Infant feeding survey 2005. London: Information Centre for Health and Social Care, 2007.

8 Colvin L, Payne J, Parsons D, Kurinczuk J), Bower C. Alcohol consumption during pregnancy in nonindigenous West Australian women. Alcohol Clin Exp Res 2007;31:276-84.

9 World Health Organization. The WHO global data bank on breastfeeding and complementary feeding. www.who.int/research/ iycf/bfcf/bfcf.asp?menu=00.

10 Phares TM, Morrow B, Lansky A, Barfield WD, Prince CB, Marchi KS, et al. Surveillance for disparities in maternal health-related behaviors - selected states, Pregnancy Risk Assessment Monitoring System (PRAMS), 2000-2001. MMWR Surveill Summ 2004;53:1-13.

11 Department of Health. Smoking kills-a white paper on tobacco. London: Stationery Office, 1998.

12 US Department of Health and Human Services. Healthy people 2010 Vols I and II. Washington, DC: US Department of Health and Human Services, Public Health Service, Office of the Secretary for Health, 2000.

13 International Center for Alcohol Policies. International guidelines on drinking during pregnancy.

2007. www.icap.org/Policylssues/DrinkingGuidelines/ PregnancyTable/tabid/254/Default.aspx.

14 World Health Organization, Unicef. Global strategy for infant and young child feeding. Geneva: WHO, 2002.

15 Madan A, Palaniappan L, Urizar G, Wang Y, Fortmann S, Gould JB. Sociocultural factors that affect pregnancy outcomes in two dissimila immigrant groups in the United States. J Pediatr 2006;148:341-6.

16 Perreira KM, Cortes KE. Race/ethnicity and nativity differences in alcohol and tobacco use during pregnancy. Am J Public Health 2004;96:1629-36.

17 Leslie JC, Diehl SJ, Galvin SL. A comparison of birth outcomes among US-born and non-US-born Hispanic women in North Carolina. Matern Child Health / 2006;10:33-8.

18 Harley K, Eskenazi B. Time in the United States, social support and health behaviors during pregnancy among women of Mexican descent. Soc Sci Med 2006;62:3048-61.

19 Singh GK, Kogan MD, Dee DL. Nativity/immigrant status, race/ ethnicity, and socioeconomic determinants of breastfeeding 
initiation and duration in the United States, 2003. Pediatrics 2007;119(suppl 1):S38-46

20 Celi AC, Rich-Edwards JW, Richardson MK, Kleinman KP, Gillman MW. Immigration, race/ethnicity, and social and economic factors as predictors of breastfeeding initiation. Arch Pediatr Adolesc Med 2005;159:255-60.

21 Gibson MV, Diaz VA, Mainous AG, Geesey ME. Prevalence of breastfeeding and acculturation in Hispanics: results from NHANES 1999-2000 study. Birth 2005;32:93-8.

22 Merewood A, Brooks D, Bauchner H, MacAuley L, Mehta SD. Materna birthplace and breastfeeding initiation among term and preterm infants: a statewide assessment for Massachusetts. Pediatrics 2006;118:e1048-54.

23 Gibson-Davis CM, Brooks-Gunn J. Couples' immigration status and ethnicity as determinants of breastfeeding. Am J Public Health 2006;96:641-6.

24 Harley K, Stamm NL, Eskenazi B. The effect of time in the U.S. on the duration of breastfeeding in women of Mexican descent. Matern Child Health J 2007;11:119-25.

25 Lara M, Gamboa C, Kahramanian MI, Morales LS, Bautista DEH Acculturation and Latino health in the United States: a review of the literature and its sociopolitical context. Annu Rev Public Health 2005;26:367-97.

26 Abraido-Lanza AF, Armbrister AN, Florez KR, Aguirre AH. Toward a theory-driven model of acculturation in public health research. $A m$ J Public Health 2006;96:1342-6.

27 Rendall M, Salt J. The foreign-born population. In: Chappell R, ed. Focus on people and migration. Basingstoke: Palgrave Macmillan, 2005.

28 White A. Social focus in brief: ethnicity 2002. London: Office for National Statistics, 2002

29 Erens B, Primatesta P, Prior G. Health survey for England 1999: the health of minority ethnic groups. London: Department of Health, 2007.

30 Plewis I. Millennium cohort study: technical report on sampling. London: Institute of Education, University of London, 2004.

31 Plewis I, Ketende S. Millennium cohort study: technical report on response. 1st ed. London: Institute of Education, University of London, 2006.

32 Hansen K. Millennium cohort study first and second surveys: a guide to the datasets. 1st ed. London: Institute of Education, University of London, 2006.

33 Office for National Statistics. Ethnic group statistics: a guide for the collection and classification of ethnicity data. London: Stationery Office, 2003.

34 Rose D, Pevalin D. A researcher's guide to the national statistics socio economic classification. London: Sage Publications, 2003.

35 Department of Health. The pregnancy book. London: Department of Health, 2006.

36 Michaelsen KF, Weaver L, Branca F, Robertson A. Feeding and nutrition of infants and young children: guidelines for the WHO
European region, with emphasis on the former Soviet countries. Copenhagen: World Health Organization, 2000.

37 Rao JNK, Scott AJ. On chi-squared tests for multiway contingency tables with cell proportions estimated from survey data. Ann Stat 1984;12:46-60.

38 McNutt L-A, Wu C, Xue X, Hafner JP. Estimating the relative risk in cohort studies and clinical trials of common outcomes. Am J Epidemiol 2003;157:940-3.

39 Zou G. A modified poisson regression approach to prospective studies with binary data. Am J Epidemiol 2004;159:702-6.

40 Li R, Scanlon KS, Serdula MK. The validity and reliability of maternal recall of breastfeeding practice. Nutr Rev 2005;63:103-10.

41 Ford RPK, Tappin DM, Schluter PJ, Wild CJ. Smoking during pregnancy: how reliable are maternal self reports in New Zealand? J Epidemiol Community Health 1997;51:246-51.

42 Stoler JM, Huntington KS, Peterson CM, Peterson KP, Daniel P, Aboagye KK, et al. The prenatal detection of significant alcohol exposure with maternal blood markers. J Pediatr 1998;133:346-52.

43 Walsh RA, Redman S, Adamson L. The accuracy of self-report of smoking status in pregnancy women. Addict Behav 1996;21:675-9.

44 Department of Health, Home Office, Department for Education and Skills, Department for Culture, Media and Sport. Safe. Sensible. Social. The next steps in the national alcohol strategy. London: Department of Health, 2007.

45 Gill PS, Kai J, Bhopal RS, Wild S. Black and minority ethnic groups. In Stevens A, Raftery J, Mant J, Simpson S, eds. Health care needs assessment, third series. Oxford: Radcliffe Medical Press, 2007.

46 Butler S, Williams M, Paterson J, Tukuitonga C. Smoking among mothers of a Pacific Island birth cohort in New Zealand: associated factors. N Z Med / 2004;117:1171.

47 Butler S, Williams M, Tukuitonga C, Paterson J. Factors associated with not breastfeeding exclusively among mothers of a cohort of Pacific infants in New Zealand. N Z Med J 2004;117:908.

48 Bonuck KA, Freeman K, Trombley M. Country of origin and race/ ethnicity: impact on breastfeeding intentions. J Hum Lact 2005;21:320-6.

49 The smoke-free (premises and enforcement) regulations 2006. London: Stationery Office, 2006.

50 Eisner MD. Banning smoking in public places. JAMA 2006;296:1178-9.

51 Scottish Parliament. Breastfeeding etc. (Scotland) act 2005. Edinburgh: Stationery Office, 2005.

52 National Conference of State Legislatures. 50 state summary of breastfeeding laws. 2008. www.ncsl.org/programs/health/breast50.htm.

53 Breastfeeding Manifesto Coalition. Breastfeeding manifesto. www. breastfeedingmanifesto.org.uk/doc/breastfeeding_manifesto.pdf.

Accepted: 11 March 2008 